\title{
Recovery of lead and cadmium ions from metal-loaded biomass of wild cocoyam (Caladium bicolor) using acidic, basic and neutral eluent solutions
}

\author{
Michael Horsfall Jnr* \\ Department of Pure and Industrial Chemistry \\ University of Port Harcourt \\ P. O. Box 402, Choba \\ Port Harcourt, Nigeria \\ Tel: 2348035079595 \\ E-mail: horsfalljnr@yahoo.com \\ Fred E. Ogban \\ Department of Chemistry \\ Delta State University \\ P. M. B 1, Abraka \\ Delta State, Nigeria \\ Tel: 234-8025434425 \\ Eyetemi E. Akporhonor \\ Department of Chemistry \\ Delta State University \\ P. M. B 1, Abraka \\ Delta State, Nigeria \\ Tel: 234-8035501947
}

\begin{abstract}
Financial support: This project was sponsored by International Foundation for Science (IFS) in collaboration with COMSTECH (The Committee on Scientific and Technological Cooperation of the Organization of Islamic Conference, Islamabad, Pakistan and INWERDAM (Inter-Islamic Network on Water Resources Development and Management, Amman, Jordania) through Grant No. W/3624-1 to Dr M. Horsfall Jnr.
\end{abstract}

Keywords: cocoyam, desorption, heavy metals removal, metal recovery, water treatment.

The effects of acidic, basic and neutral reagents on the recovery of $\mathrm{Pb}^{2+}$ and $\mathrm{Cd}^{2+}$ from metal-loaded biomass of wild cocoyam ( $C$. bicolor) were investigated by eluting the biomass in five successive cycles using $0.01 \mathrm{M} \mathrm{HCl}$, 0.1 M HCl, 0.01 M NaOH, 0.1 M NaOH and distilled water at different contact times. The data showed that the ease of metal ion recovery from metal -loaded biomass by the eluent solutions is of the order $0.01 \mathrm{M}$ $\mathrm{HCl}>0.1 \mathrm{M} \mathrm{HCl}>0.01 \mathrm{M} \mathrm{NaOH}>0.1 \mathrm{M} \mathrm{NaOH}>$ distilled water. Over $94 \% \mathrm{~Pb}^{2+}$ and $74 \% \mathrm{Cd}^{2+}$ of the initially adsorbed metals were recovered by $0.01 \mathrm{M} \mathrm{HCl}$, while $<20 \%$ of both metals was recovered by basic reagent. Distilled water recovered less than $9 \%$ of both metal ions from the biomass. Macroscopic changes were also observed as the concentration of recovery reagent increased. This study has demonstrated that the selection of a recovery reagent for metal ions on a biomaterial should give consideration to the reusability of the biomass.

Metal ion recovery studies from spent biomass are an important aspect of the waste management and environmental remediation goals. These studies may help to elucidate the nature of recovery of metal ions from wastewater and the recycling of adsorbent. The possibility of regeneration of spent biosorbent is crucially important to keeping the process costs of remediation down and to opening the possibility of recovering the metal(s) extracted from the liquid phase. The deposited metals are washed out (recovered) and biosorbent regenerated for another cycle of application. The recovery process should result in (1) -highconcentration metal effluent; (2) -undiminished metal uptake upon re-use; (3) -no biosorbent physico-chemical damage. The recovery of metal ions and sorbent regeneration studies might require somewhat different methodologies. Screening for the most effective regenerating solution is the beginning. Different affinities of metal ions for the biosorbent result in certain degree of metal selectivity on the uptake. Similarly, selectivity may be achieved upon the elution-recovery operation which may serve as another means of eventually separating metals from one another if desirable.

A number of studies have demonstrated the feasibility of

*Corresponding author 
Table 1. Surface properties of pure C. bicolor biomass using particle size $(\mu \mathrm{m})$ of 100.

\begin{tabular}{|l|c|}
\hline \multicolumn{1}{|c|}{ Surface properties } & Amount \\
\hline Bulk density, $\mathrm{g} \mathrm{cm}^{-1}$ & $1.63 \pm 0.11$ \\
\hline Specific surface area, $\mathrm{m}^{2} \mathrm{~g}^{-1}$ & $32.91 \pm 1.22$ \\
\hline Porosity, \% & $59.31 \pm 1.14$ \\
\hline Pore volume, $\mathrm{cm}^{3} \mathrm{~g}^{-1}$ & $0.61 \pm 0.03$ \\
\hline Cation exchange capacity, $\mathrm{meq}^{-1}$ & $25.69 \pm 0.58$ \\
\hline Surface charge density, meq ${ }^{-2}$ & $0.78 \pm 0.04$ \\
\hline
\end{tabular}

using plant biomass to remove heavy metal ions from aqueous solutions (sago waste; Quek et al. 1998, cassava waste; Abia et al. 2003, banana pith; Low et al. 1995, Medicago sativa (Alfalfa); Gardea-Torresdey et al. 1998; and Spagnum Moss Peat; Ho et al. 1995) just to mention a few. Each of these studies have also mentioned the importance of recovery of metal ions from the biomass and eventual regeneration of the spent biomass. However, very little has appeared in the literature as a major study on the recovery of adsorbed metals from the biomass (GardeaTorresdey et al. 1998; Zhou et al. 1998; Chu and Hashim, 2001). C. bicolor biomass has been used as an effective adsorbent for metal ions from aqueous solution (Horsfall and Spiff, 2004a; Horsfall and Spiff, 2004b; Horsfall and Spiff, 2005a; Horsfall and Spiff, 2005b). However, most biomass in its native form may not be suitable for process applications as they may disintegrate under the harsh conditions of wastewater processing, especially in cases where the biomass is exposed to a stronger reagent to recover the adsorbed metal ions and regenerate the biomass for reuse. It is because of this reason we have used several desorption reagent with different strength in order to assess the reusability of the biomass after recovery. The purpose of this study is therefore to examine the effect of acidic, basic and neutral eluents in the recovery of $\mathrm{Pb}^{2+}$ and $\mathrm{Cd}^{2+}$ from biomass of wild cocoyam (C. bicolor).

\section{MATERIALS AND METHODS}

\section{Materials}

Biomass preparation and surface characterization. $C$. bicolor (wild cocoyam) biomass was used in this study. The preparation and estimation of the surface characteristics of the biomass has been reported elsewhere (Horsfall and Spiff, 2004a; Horsfall and Spiff, 2004b; Horsfall and Spiff, 2005a; Horsfall and Spiff, 2005b), which are outlined below. Before the batch adsorption experiment, the wild cocoyam corms were washed with deionised water, cut into small pieces, air-dried for two days in the laboratory temperature and then dried in an oven (Gallen Kamp, model OV-160, England) at $105^{\circ} \mathrm{C}$ to constant weight. The oven dried materials were grounded and screened through $100 \mu \mathrm{m}$ Tyler screen sieve to obtain a finely divided biomass. The biomass was activated by soaking in excess $0.3 \mathrm{M} \mathrm{HNO}_{3}$ for $24 \mathrm{hrs}$. This was followed by washing the activated biomass thoroughly with deionised water until a
$\mathrm{pH}$ of $7.1 \pm 0.1$ was attained and then dried in the air. The air dried activated biomass was further dried in the oven at $45^{\circ} \mathrm{C}$ with occasional mixing to constant weight. The activation process removes any debris or soluble biomolecules that might interact with metal ions, and also all biogenic metal ions in the biomass. The activated biomass samples were characterized in terms of bulk density, surface area, porosity, pore volume, cation exchange capacity, and surface charge density. The procedures for characterizing these parameters have been previously described and reported elsewhere (Horsfall and Spiff, 2004a). The surface properties of the pure wild cocoyam biomass are presented in Table 1.

FTIR characterization of biomass. The finely divided biomass was analyzed to determine their functional groups using a Fourier Transform Infrared Spectroscopy (Shimadzu IR Prestige - 21, FTIR - 84005) using KBr as the rock salt. The finely divided solid biomass was mixed with a disc using a hydraulic press and mould. The mixture on the disc was inserted in the path of the IR beam and held in position.

\section{Methods}

Batch adsorption experiment. Batch experiments were first conducted to load the Caladium bicolor biomass with metal ions separately. In this experiment $500 \mathrm{mg}$ of the biomass samples with particle size $100 \mu \mathrm{m}$ was weighed and placed in pre-cleaned test tubes in triplicates. An initial metal ion concentration of $100 \mathrm{mg} / \mathrm{L}$ were made from spectroscopic grade standards of $\mathrm{Pb}^{2+}$ obtained from $\mathrm{Pb}(\mathrm{NO} 3) 2$ and $\mathrm{Cd}^{2+}$ obtained from $\left.\mathrm{Cd}(\mathrm{NO} 3) 2.4 \mathrm{H} 2 \mathrm{O}\right)$. The two metal solutions made separately were adjusted to $\mathrm{pH}$ 5.0 with concentrated $\mathrm{HCl}$ solution. Fifty millilitres of each metal solution were added to each tube containing the biomass and equilibrated for $2 \mathrm{hrs}$ by shaking at $29^{\circ} \mathrm{C}$. The biomass suspensions were centrifuged for five minutes at $3000 \mathrm{x}$ g, gently washed with deionised water to remove unabsorbed metal ions and centrifuged again. The levels of $\mathrm{Pb}^{2+}$ and $\mathrm{Cd}^{2+}$ were analysed by digesting some portion of the biomass using $\mathrm{HNO}_{3}$ and $\mathrm{HClO}_{4}$ and the metals content measured by Flame Atomic Absorption Spectrometry (FAAS) Varian-Techron AA-6, and found to be $49.53 \mathrm{mg} / \mathrm{g}$ and $48.20 \mathrm{mg} / \mathrm{g}$ respectively.

Batch recovery experiment. $250 \mathrm{mg}$ of metal-laden $C$. bicolor biomass were placed in several flasks containing 50 


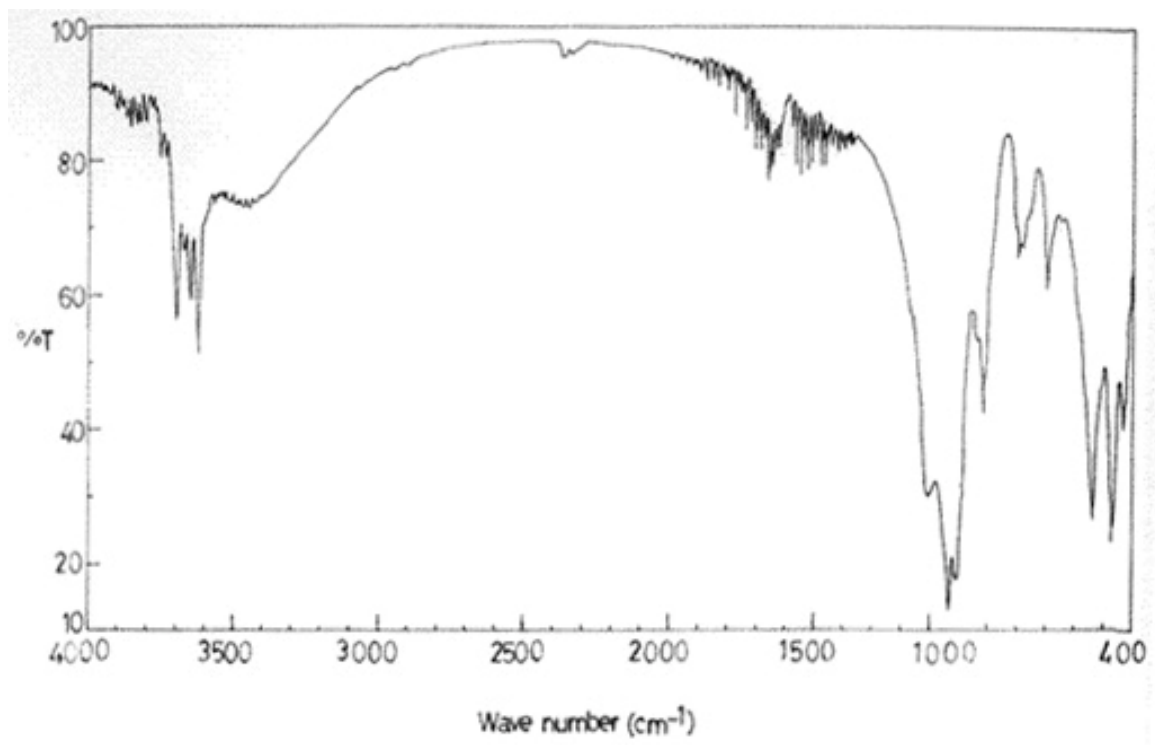

Figure 1. FTIR Spectra of the biomass sample.

$\mathrm{mL}$ of $0.01 \mathrm{M} \mathrm{HCl}, 0.1 \mathrm{M} \mathrm{HCl}, 0.01 \mathrm{M} \mathrm{NaOH}, 0.1 \mathrm{M}$ $\mathrm{NaOH}$ or pure water. The flasks were shaken for $20,40,60$, $80,100,120$ and $140 \mathrm{~min}$ at $29^{\circ} \mathrm{C}$ and agitated on a mechanical shaker at $150 \mathrm{rpm}$. At the end of each contact time the suspensions were centrifuged at $2500 \mathrm{x}$ g for 5 min. For each fixed time interval, five cycles of recovery equilibrium experiments were conducted to asses the reusability of the biomass. The solutions from the five cycles were combined and evaporated gently to decrease the final volume to $10 \mathrm{~mL}$ and digested using $1.0 \mathrm{M} \mathrm{HNO}_{3}$ and made up to $50 \mathrm{~mL}$. The metal content $\left(\mathrm{Pb}^{2+}\right.$ and $\left.\mathrm{Cd}^{2+}\right)$ in the digest were measured in triplicates by FAAS.

\section{Data evaluation}

The amounts of metal ion remaining on the biomass as a function of time $\left(q_{t}\right)$ were estimated after determining the amount of metal ion in the recovery reagents and subtracting from the initial amount of metal ion on the biomass $\left(q_{e}\right)$ by using a mass balance equation (Equation 1):

$$
q_{t}=q_{e}-\frac{v}{m} C_{*}
$$

where $q_{t}$ isthe actual metal ion concentration recovered from the biomass $(\mathrm{mg} / \mathrm{g})$ and $C_{t}$ is concentration of metal ion remaining in solution after recovery $(\mathrm{mg} / \mathrm{L})$ at time $t$ (min), respectively, $m$ is mass of biomass used $(\mathrm{g})$ and $v$ is the volume of eluent solution used $(\mathrm{mL})$.

\section{RESULTS AND DISCUSSION}

\section{Biomass characterization}

The surface area was determined to be $32.91 \pm 1.22\left(\mathrm{~m}^{2} \mathrm{~g}\right.$ ${ }^{1}$ ), while the bulk density, porosity and pore volume were
$1.63 \pm 0.11\left(\mathrm{~g} \mathrm{~cm}^{-1}\right), 59.31 \pm 1.14(\%)$ and $0.61 \pm 0.03\left(\mathrm{~cm}^{3}\right.$ $\left.\mathrm{g}^{-1}\right)$ respectively. Furthermore, the cation exchange capacity $\left(25.69 \pm 0.58 ; \mathrm{meq} \mathrm{g}^{-1}\right)$ and surface charge density $(0.78 \pm$ 0.04; meq $\mathrm{m}^{-2}$ ) were also determined. The FTIR spectra of the investigated $C$. bicolor biomass are shown in Figure 1. Inspection of these spectra reveals the presence of the following peaks at wave no. $3400 \mathrm{~cm}^{-1}$ representing - OH stretching frequency; several peaks at wave no $1650 \mathrm{~cm}^{-1}$ and $1050 \mathrm{~cm}^{-1}$ representing $-\mathrm{C}=\mathrm{N}$ of amides and $\mathrm{C}-\mathrm{O}$ of alcohol, and peak at $1709 \mathrm{~cm}^{-1}$ for $\mathrm{C}=\mathrm{O}$ group of ketones. The peak at $2300 \mathrm{~cm}^{-1}$ represents a $\mathrm{C}-\mathrm{H}$ saturated hydrocarbon of chain. On the overall the spectra indicated the presence of hydroxyl, carboxyl, amide and possibly carbonyl group.

The applicability of plant biomass for metal ion recovery from waste stream requires that the biomass be regenerated efficiently so that the bound metal can be recovered in concentrated form and the biomass reused. The data as presented in Figure 2 gives the percent recovery of $\mathrm{Pb}^{2+}$ and $\mathrm{Cd}^{2+}$ as a function of time. It is apparent from the figure that recovery in the acidic media was quite rapid with equilibrium recovery achieved within the first 15 - $25 \mathrm{~min}$ of contact time. It is also noticeable from the figure that increased contact time does not significantly increased recovery after $25 \mathrm{~min}$. From the metal-laden biomass, over $90 \%$ and $75 \%$ of $\mathrm{Pb}^{2+}$ sorbet were recovered by acidic media concentrations of $0.01 \mathrm{M} \mathrm{HCl}$ and $0.1 \mathrm{M} \mathrm{HCl}$ respectively, while the amount of $\mathrm{Cd}^{2+}$ recovered at the same acidic media concentrations were 80.52 and $78.15 \%$ respectively. In the case of recovery in basic media, a rapid phase of recovery was observed followed by a relatively slow phase before apparent recovery equilibrium was reached. The fast region occurred during the first $20 \mathrm{~min}$ of contact time. However, at the end of the 20 min recovery, only about $12.11 \%\left(\mathrm{~Pb}^{2+}\right) ; 23.44 \%\left(\mathrm{Cd}^{2+}\right)$ and $13.64 \%$ 


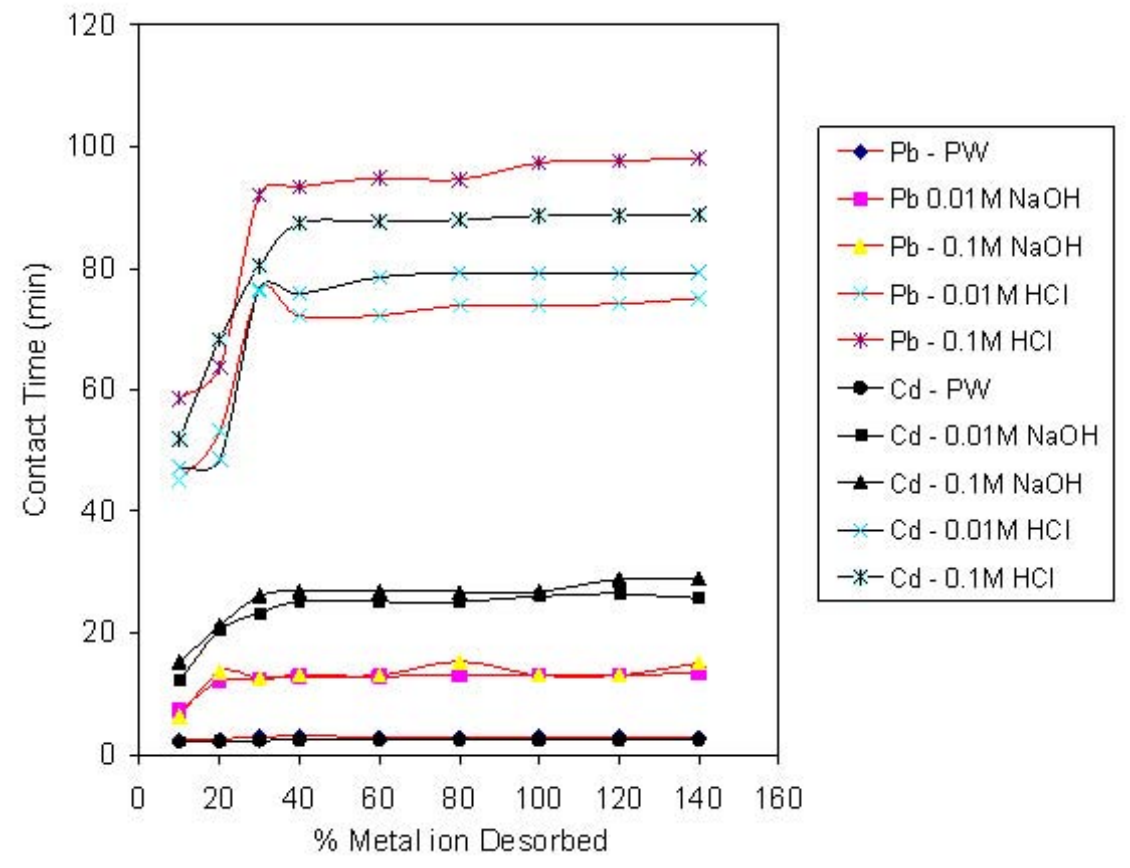

Figure 2. Effect of acidic, basic and neutral media on the recovery of $\mathrm{Pb}^{2+}$ and $\mathrm{Cd}^{2+}$ from Caladium bicolor biomass.

$\left(\mathrm{Pb}^{2+}\right) ; 26.13 \%\left(\mathrm{Cd}^{2+}\right)$ were recovered from the metal-laden biomass in the basic media with concentrations of $0.01 \mathrm{M}$ $\mathrm{NaOH}$ and $0.1 \mathrm{M} \mathrm{NaOH}$ respectively. A poor recovery was also observed for distilled water in which less than $3 \%$ of sorbet $\mathrm{Pb}^{2+}$ and $\mathrm{Cd}^{2+}$ were recovered from the metal-laden biomass. The highest metal recovery from the metal-laden C. bicolor biomass was observed in acidic media. This is because in acidic medium the carboxyl, carbonyl or hydroxyl groups in the biomass become protonated and does not attract the positively charged metal ions and therefore releases the metal ions into recovery solution. Again, in acidic medium, the protons in solution replaces the metal ions on the biomass surface, while the apparent poor recovery of less than $20 \%$ observed in basic media such as $\mathrm{NaOH}$, may be due to the coordinating ligands being deprotonated, hence bound-metal ions finds it difficult to be detached from the biomass. A control experiment using distilled water at $\mathrm{pH} 7.0$ demonstrated negligible metal recoveries within the entire contact time tested in this study. The data in this investigation revealed that, on a comparative basis, recovery of bound metal ion from the biomass is greater for $\mathrm{Pb}^{2+}$ than $\mathrm{Cd}^{2+}$ in all the recovery media investigated. This observation may be as a result of the stronger $\mathrm{Cd}^{2+}$ - biomass bond as a result of smaller ionic radius. It has been severally observed (Okiemen et al. 1987; Ho et al. 1995; Horsfall and Spiff, 2004a; Horsfall and Spiff, 2004b; Horsfall and Spiff, 2005a; Horsfall and Spiff, 2005b) that, the smaller the ionic radius the greater the tendency of such metal ions to stick to binding sites. The ionic radii of $\mathrm{Pb}^{2+}$ and $\mathrm{Cd}^{2+}$ are $1.20 \AA$ and $0.97 \AA$, respectively. The larger ionic radius of $\mathrm{Pb}^{2+}$ may have resulted in steric hindrance on the binding surfaces and subsequently releases greater amount into recovery media upon slight agitation. Again several functional groups on the surface of a biomass are capable of interacting with heavy metal ions (Ho et al. 1995). These groups also found in C. bicolor exhibits different binding affinities for metal ions. The binding of $\mathrm{Cd}^{2+}$ to high affinity sites due to its small ionic size may be the principal factor responsible for the observed fractions of $\mathrm{Cd}^{2+}$ that it's recovery was less than that of $\mathrm{Pb}^{2+}$.

Although complete desorptions were not achieved, it is clear from the results that the $\mathrm{HCl}$ acidic media is a better eluent than the $\mathrm{NaOH}$ basic media. This is because acidic media contain high concentrations of protons present in the recovery reagent which may displace bound metal ion from the active sites on the biomass than hydroxonium ions. Macroscopic observations indicate that the initial biomass weight and colour changed in the acid and basic media with these changes increasing with increase in eluent concentration. Although distilled water is ineffective in recovering the metal ions on the biomass, it leaves the biomass for several recyclability. Generally, the influence of the recovery media tested for the recovery of $\mathrm{Pb}^{2+}$ and $\mathrm{Cd}^{2+}$ from the biomass is of the order $0.01 \mathrm{M} \mathrm{HCl}>0.1 \mathrm{M}$ $\mathrm{HCl} \gg>0.01 \mathrm{M} \mathrm{NaOH}>0.1 \mathrm{M} \mathrm{NaOH}>>$ distilled water.

\section{CONCLUDING REMARKS}

The recovery with dilute hydrochloric acid solution was found to be better option in all the reagents tested because it leaves the biomass for further reuse. Since a single cycle of adsorption-desorption equilibrium studies is not enough to sufficiently access the recovery capacity of an efluent, 
hence, five cycles was tested. The results of the investigation are quite useful for metal ion recovery eluent selection using batch or stirred flow reactors. Additional research is on-going to elucidate the recovery efficiency of this and other adsorbent with respect to volume of eluent, biomass reloading efficiency and biomass regeneration/recycling.

\section{REFERENCES}

ABIA, A.A.; HORSFALL, M. Jr. and DIDI, O. The Use of Chemically Modified and Unmodified Cassava Waste for the Removal of $\mathrm{Cd}, \mathrm{Cu}$ and $\mathrm{Zn}$ ions from Aqueous Solution. Bioresource Technology, December 2003, vol. 90 , no. 3 , p. $345-348$.

CHU, K. H. and HASHIM, M.A. Desorption of copper from polyvinyl alcohol-immobilized seaweed biomass. Acta Biotechnologica, November 2001, vol. 21, no. 4, p. 295-306.

GARDEA-TORRESDEY, J.L.; GONZALEZ, J.H.; TIEMANN, K.J.; RODRIGUEZ, $\mathrm{O}$ and GAMEZ, G. Phytofiltration of Hazardous cadmium, chromium, lead and zinc ions by biomass of Medicago sativa (Alfalfa). Journal of Hazardous Materials, January 1998, vol. 57, no. 1-3, p. 29-39.

HO, Y.S.; JOHN WASE, D.A. and FORSTER, C.F. Batch Nickel Removal from Aqueous Solution by Sphagnum Moss Peat. Water Research, May 1995, vol. 29, no. 5, p.1327-1332.

HORSFALL, Michael Jnr. and SPIFF, Ayebaemi I. Adsorption of Metal Ions from Mixed Metal Solutions on Caladium Bicolor (Wild Cocoyam) Biomass Surface. Journal of Corrosion Science and Technology, 2004a, vol. 2, p. 12-18.

HORSFALL, Michael Jnr. and SPIFF, Ayebaemi I. Studies on the Effect of $\mathrm{pH}$ on the Sorption of $\mathrm{Pb}^{2+}$ and $\mathrm{Cd}^{2+}$ ions from aqueous solutions by Caladium bicolor (Wild Cocoyam) Biomass. Electronic Journal of Biotechnology [online]. 15 December 2004b, vol. 7, no. 3. Available from Internet:

http:/www.ejbiotechnology.info/content/vol7/issue3/full/8/ index.html. ISSN 0717-3458.

HORSFALL, Michael Jnr. and SPIFF, Ayebaemi I. Effect of Metal ion Concentration on the Biosorption of $\mathrm{Pb}^{2+}$ and $\mathrm{Cd}^{2+}$ by Caladium bicolor (Wild Cocoyam). African Journal of Biotechnology, February 2005a, vol. 4, no. 2, p. 191-196.

LOW, K.S.; LEE, C.K. and LEO, A.C. Removal of metals from electroplating wastes using banana pith. Bioresource Technology, 1995, vol. 51, no. 2-3, p. 227-231.

OKIEMEN, F.E.; MAYA, A.O. and ORIAKHI, C.O. Sorption of cadmium, lead, and zinc ions on sulphur- containing chemically modified cellulosic materials. International Journal of Environmental Analytical Chemistry, 1987, vol. 32, p. 23-27.

QUEK, S.Y.; WASE, D.A.J. and FORSTER, C.F. The use of Sago Waste for the Sorption of lead and Copper. Water $S A$, July 1998 , vol. 24 , no. 3, p. 251-256.

ZHOU, J.L.; HUANG, P.L. and LIN, R.G. Sorption and Desorption of $\mathrm{Cu}$ and $\mathrm{Cd}$ by macroalgae and microalgae. Environmental Pollution, 1998, vol. 101, no. 1, p. 67-75. 